\title{
THE INTENTIONAL USE OF LEAD-TIN ORANGE IN INDIAN ISLAMIC GLAZES AND ITS PRELIMINARY CHARACTERIZATION*
}

\author{
M. S. GILL† and TH. REHREN \\ UCL Qatar, P.O. Box 25256, Georgetown Building, Hamad bin Khalifa University, Doha, Qatar
}

\begin{abstract}
We describe the historical appearance, composition and texture of a little-known orange pigment in 17th-century northern India. The pigment shares similarities with lead-tin yellow type II, but has between 6 and 7 wt\% zinc oxide instead of silica as a minor element in its structure, in addition to the dominant lead and tin oxide. The consistency of its occurrence and composition across several important and highly decorated monuments and relatively wide chronological and geographical ranges of use indicate the controlled and intentional production of this pigment. We propose to use the name lead-tin orange for this material, indicating its similarity to lead-tin yellow but highlighting its independent character and distinct colour.
\end{abstract}

\section{KEYWORDS: LEAD-TIN YELLOW, LEAD-TIN ORANGE, GLAZED TILES, INDIA, ZINC, CHARACTERIZATION, SPOT ANALYSIS, SEM, RAMAN SPECTROSCOPY}

\section{INTRODUCTION}

Amongst the repertoire of colourants employed in Mughal Islamic glazed tiles from India is lead-tin yellow, an opacifier and pigment known to exist from antiquity, with reported use from the second century BCE to the 18th century CE (Clark et al. 1995; Tite et al. 2008). Previous studies have demonstrated that lead-tin yellow is known to exist in two forms. Type $\mathrm{I}, \mathrm{Pb}_{2} \mathrm{SnO}_{4}$ is used as a pigment in paintings (Rooksby 1964; Kühn 1968; Clark et al. 1995). Lead-tin yellow type II, the variant principally employed in glass as an opacifier or colourant, has the formula $\mathrm{Pb}(\mathrm{Sn}, \mathrm{Si}) \mathrm{O}_{3}$ or $\mathrm{PbSn}_{1-x} \mathrm{Si}_{x} \mathrm{O}_{3}$ and a crystal structure different to that of type I. The type II form, which has less lead and incorporates silicon in the crystal structure through the partial replacement of tin, is prepared by heating a mixture of pre-synthesized lead-tin yellow type I and silica between temperatures of 800 and $950^{\circ} \mathrm{C}$, beyond which it is known to decompose to its constituents (Rooksby 1964; Kühn 1968; Clark et al. 1995), or by heating the oxides of lead and tin with a small amount of glass as a flux (Heck et al. 2003). Analytically, they are distinguished primarily through their different levels of lead and tin oxide, with type I having an ideal composition of $\sim 75 \mathrm{wt} \% \mathrm{PbO}$ and $25 \mathrm{wt} \% \mathrm{SnO}_{2}$, and type II of $\sim 60 \mathrm{wt} \% \mathrm{PbO}$ and $40 \mathrm{wt} \% \mathrm{SnO}_{2}$, with variable amounts of $\mathrm{SiO}_{2}$ substituting for $\mathrm{SnO}_{2}$.

The detection of two varieties of lead-tin yellow type II particles in yellow and green glazes, one with associated silica content and the other significantly with an associated zinc content was first established by the authors (Gill and Rehren 2011) on the analyses of 17th-century glazed tiles from two sites in northern India. This was later corroborated by similar findings reported on the analyses of yellow glazes from tiles on contemporaneous monuments in Lahore,

\footnotetext{
*Received 11 May 2013; accepted 20 August 2013

$\dagger$ Corresponding author: email maninder.gill.11@ucl.ac.uk

(C) 2013 The Authors.

Archaeometry published by John Wiley \& Sons Ltd on behalf of University of Oxford.

This is an open access article under the terms of the Creative Commons Attribution License, which permits use, distribution and reproduction in any medium, provided the original work is properly cited.
} 
Pakistan (Gulzar et al. 2012). Further investigations now carried out on a wide range of glazes from five Mughal period (1526-1857) monuments in northern India reveal that the type II form was used in yellow, green and orange glazes. Of these, the orange glazes appear to be coloured exclusively by lead-tin yellow particles with associated zinc content. From a survey of extant tile-work on the same monuments, it is clear that the orange coloured tiles are a purposeful part of the artistic composition and not an accidental variation in the tone of yellow tiles employed, indicating their deliberate manufacture and thereby the intentional production and use of a lesser known version of the colourant (Fig. 1). This study reports the archaeological occurrence of this colourant, for which we suggest the name lead-tin orange, in several monuments of Mughal India.

The aim of this paper is to provide further information regarding lead-tin orange, a ternary oxide of lead, tin and zinc, in Mughal Islamic tiles, and to present preliminary data for its characterization. For this purpose, glaze layers of yellow, green and orange tiles from five monuments in northern India, namely the Tomb of Shagird (17th century), Sheesh Mahal (17th century) and Dakhini Sarai (17th century) in Punjab, and Nila Gumbad (17th century) and Sabz Burj (16th century) at Delhi, were analysed. Particular attention was paid to the nature and composition of lead-tin yellow and lead-tin orange particles distributed within the glazes.

\section{MATERIALS AND METHODS}

The sites were first visited for an in situ appraisal of their extant tile-work. Tiles on the Punjab monuments were found to be in the true tile-mosaic technique, the multicoloured mosaic patterns formed through the cutting, shaping and assembling of small tile pieces derived from larger monochrome tiles, whereas those at Delhi were seemingly dominated by largely uncut monochrome tiles that had been cast-moulded to shape. Significantly, only the glazes on the three tile-mosaic monuments in Punjab, Tomb of Shagird, Dakhini Sarai and Sheesh Mahal, were found to have a palette that included an orange colour. Yellow- and green-coloured glazes were, however, found across all the monuments. Fragments of available monochrome tiles were then collected from the site administrators on request. Due to local regulations, sampling directly from the monuments was not permissible, and only a limited number of samples that had fallen off the buildings and were in the custody of the caretakers could be utilized for analyses.

While later repairs are recorded as having taken place at Tomb of Shagird and Sabz Burj, the new tiles employed at these sites differ both outwardly and in material character. New tiles at Sabz Burj are modern ceramic tiles of a blue colour only, while the non-original tiles at Tomb of Shagird can be distinguished through both their surface finish and their microstructural characteristics. The newer tiles here have glaze layers of a rougher texture and comparatively inferior finish as compared to original tile-mosaic specimens. They also differ by having no slips, having clearly developed inter-particle glass in the bodies, and bear thicker glazes of $\sim 400 \mu \mathrm{m}$ thicknesses. Typical 17th-century tile-mosaic specimens, at this site and others, have very fine and thin glaze layers that are of $\sim 200 \mu \mathrm{m}$ thickness, have little inter-particle glass and a distinct slip layer (Fig. 2). No repairs are recorded to have taken place at Sheesh Mahal, Dakhini Sarai and Nila Gumbad. Sampled specimens from Sheesh Mahal and Dakhini Sarai, like those from Tomb of Shagird, conform to the typical characteristics of tile-mosaic specimens as described above. All the samples taken thus represent the original tile-work as installed. 


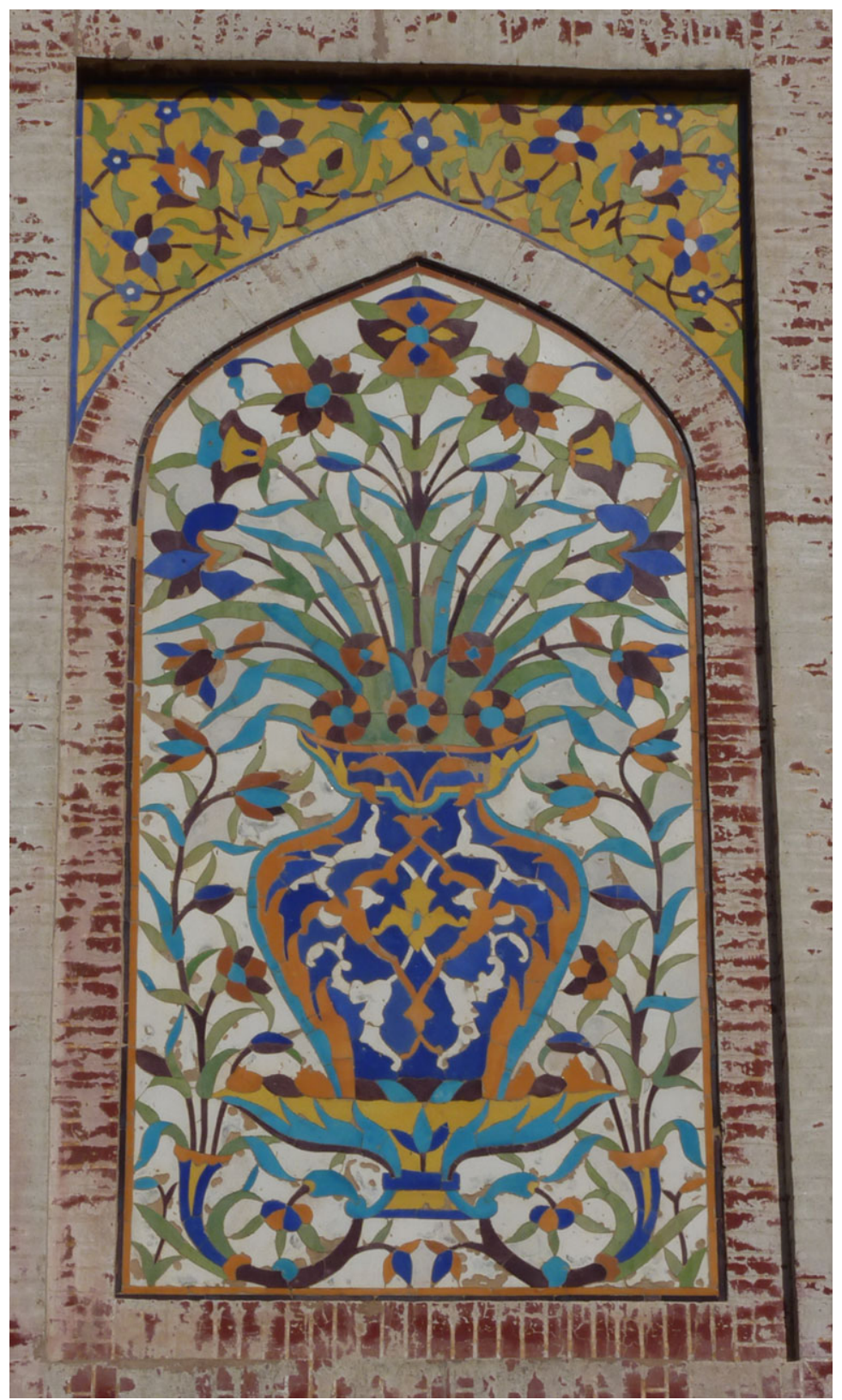

Figure 1 A detail of a tile-mosaic panel from the Tomb of Shagird, Punjab. Orange-coloured tiles can be seen to be a deliberate part of the artistic composition and are visually easily distinguishable from their yellow counterparts by their mellow terracotta hue. 

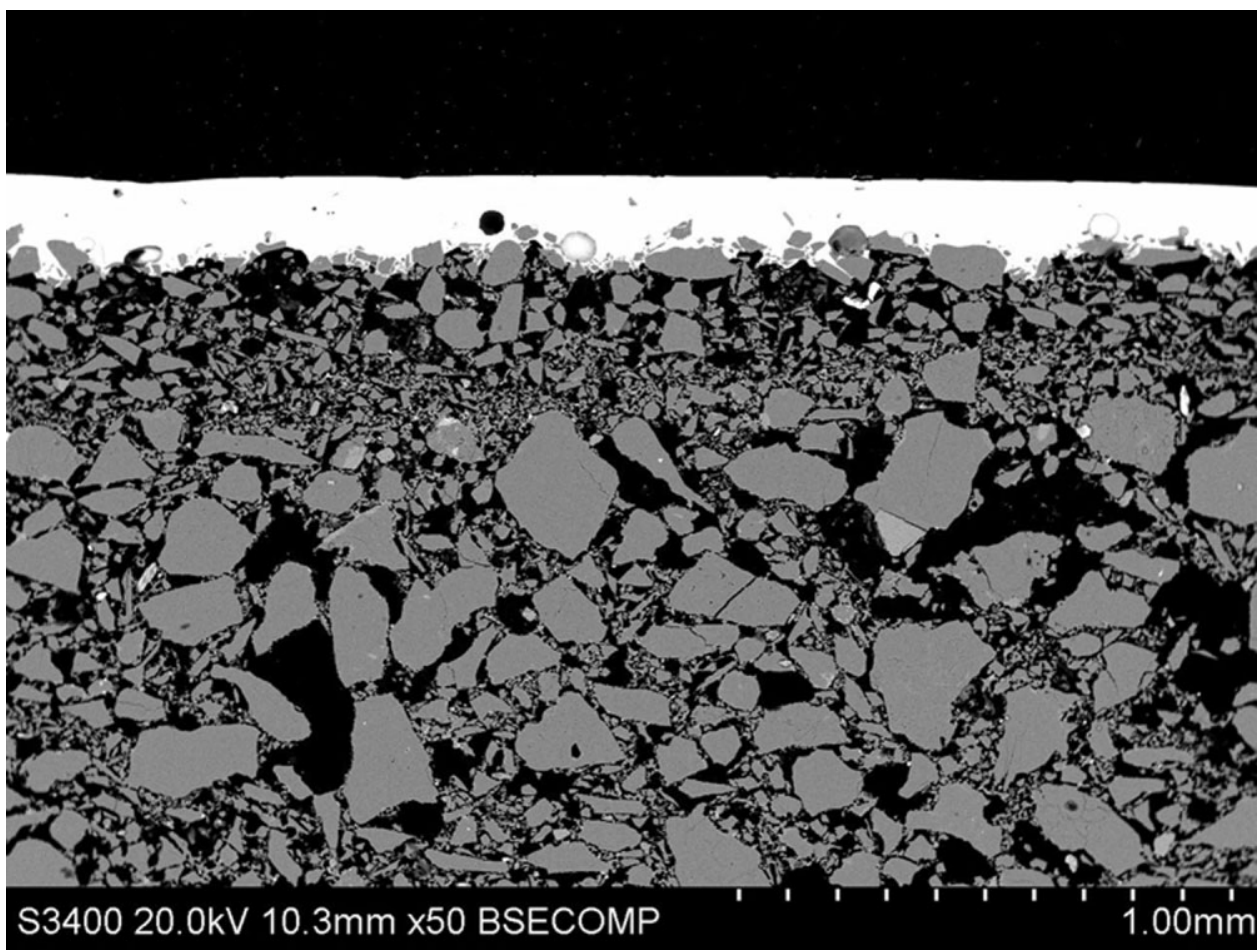

Figure 2 A backscattered electron SEM micrograph of a polished section of a tile-mosaic sample from Sheesh Mahal, Punjab. The thin glaze layer of $200 \mu \mathrm{m}$ thickness and the distinct slip layer are characteristic features of tile-mosaic samples from the Punjab region. The body can be seen to be comprised almost entirely of quartz grains of varying size and shape, mostly with rounded edges.

Polished cross-sections of 14 monochrome tile samples sourced from the sites were mounted in resin blocks for examination in a JEOL electron probe microanalyser (JXA 8600), equipped with a wavelength-dispersive spectrometer (WDS) and an Oxford Instruments energy-dispersive spectrometer (EDS). Quantitative analyses of the glaze layers were carried out using the WDS at $15 \mathrm{kV}, 50 \mathrm{nA}$ through area scans at $800 \times$ magnification corresponding to approximately $100 \times 140 \mu \mathrm{m}$ of scanned expanse on the sample surface. Scanned areas for bulk compositional analyses include colourant or opacifier particles while avoiding bubbles, pores and visible quartz grains, which are especially frequent near the body/glaze interface. Smaller area scans of clear portions of a few glazes were also carried out at the same settings. Spot analyses of bright particles distributed within the glaze layers were undertaken utilizing the EDS at $20 \mathrm{kV}$ at magnification in the range 1500-2000×, and by WDS spot analyses in the case of two sites for corroborative measurements, at $3000 \times, 15 \mathrm{kV}$ and $15 \mathrm{nA}$. The stability of the beam current was monitored by calibrating against a cobalt standard, and the accuracy of the systems employed checked against Corning $\mathrm{A}$ and $\mathrm{C}$ reference glasses. All quantitative results are reported as weight per cent oxides with oxygen determined by stoichiometry; the reported values are the average of between three and five analyses spread over the glaze layer. In the case of spot analyses, each result, calculated and reported both as atomic and as weight per cent, reports the composition of 
distinct pigment particles. Findings from a total of 50 particles from the glaze layer of 12 of the 14 samples are thus presented. For the orange glazes, the spot analyses are representative of a much higher number of investigations actually carried out, approximately 8-10 particles in each such glaze being examined.

Raman spectra of particles in the glaze layers of yellow and orange samples from the Tomb of Shagird were obtained using a Nicolet Almega XR-dispersive Raman spectrometer equipped with a charge-coupled device detector, coupled to an Olympus Raman microscope. The exciting wavelength was 532/780 $\mathrm{nm}$ of a Nd:YAG laser at an exposure time of $10 \mathrm{~s}$. The laser power on the sample surface was set to a value between $4 \mathrm{~mW}$ and $25 \mathrm{~mW}$.

\section{RESULTS}

All the tiles examined are found to be similar in their structure. They have porous quartz-rich 'stonepaste' bodies with small bright particles of a colourant or opacifier distributed throughout an overlying glaze layer, typical of Islamic technology (Mason and Tite 1994). The glaze layers of tiles from the Delhi sites are substantially thicker, in the range 400-600 $\mu \mathrm{m}$, compared to those from the Punjab, which are only $180-220 \mu \mathrm{m}$ across. Differences in the shape, size and distribution of quartz grains making up the tile bodies are also noticeable between the samples from the two regions, suggestive of regional production variances. Particularly distinctive are the rounded shapes and edges of larger grains in the Punjab tile-mosaic bodies, as opposed to the greater angularity of large grains found in the bodies from the Delhi sites, where the grains are also better sorted. Better developed inter-particle glass is also noticeable in the Delhi bodies as compared to the Punjab specimens.

The glazes have relatively similar contents of soda and lead oxide, the former in the range $10-15 \%$ and slightly higher for the latter from 10 to $20 \%$; except for TS/02 and DKS/02, where the lead oxide content is abnormally high, reaching almost $30 \mathrm{wt} \%$ (Table 1). Silica is typically in the range 50-55 wt \% . On the basis of their alumina content, the glazes form two broad groups. Those with higher alumina, $>5 \mathrm{wt} \%$, together with lower magnesia and potash, are found in all samples from Delhi. As a group, these are reflective of an Indian glass-making tradition using a mineral soda flux (Dussubieux et al. 2010). The others from Punjab with lower alumina values, in the range $1.3-1.7 \%$, and higher magnesia and potash, form a second group fluxed possibly with plant ash. Both groups are remarkably low in their lime content, not exceeding $2 \mathrm{wt} \% \mathrm{CaO}$ in the alumina-rich glazes, and falling between 2 and $3 \mathrm{wt} \%$ in the others.

The concentrations of lead, tin and zinc oxides in the glazes follow an interesting pattern. Comparing area analyses of pigmented and of clear areas of the glazes, it becomes apparent that the levels of lead and zinc oxide in the pigmented areas of the Punjab tiles are only marginally higher than in the clear areas (Table 2). Tin oxide, however, rarely exceeds $1 \mathrm{wt} \%$ in the clear parts, but reaches $3-4 \mathrm{wt} \%$ in the pigmented areas. This suggests that the glass phase is rich in both lead and zinc oxide, but contains only a little tin oxide, even though the pigment particles contain more than $31 \mathrm{wt} \% \mathrm{SnO}_{2}$. The zinc oxide content of the pure glass melt is notably similar to the pigmented bulk values in the orange Punjab glazes. In both, it falls to between 1.5 and $2.5 \mathrm{wt} \% \mathrm{ZnO}$, while the pigment itself has about 6-7 wt $\% \mathrm{ZnO}$. In contrast, zinc oxide is seemingly absent in clear areas, and present only in quantities below one third of $1 \%$ in pigmented areas of the Delhi high alumina group. The green glazes differ from the yellow ones only by an added $3 \mathrm{wt} \%$ copper oxide, suggesting that they were made in the same workshop, or at least using the same recipe and raw materials. 


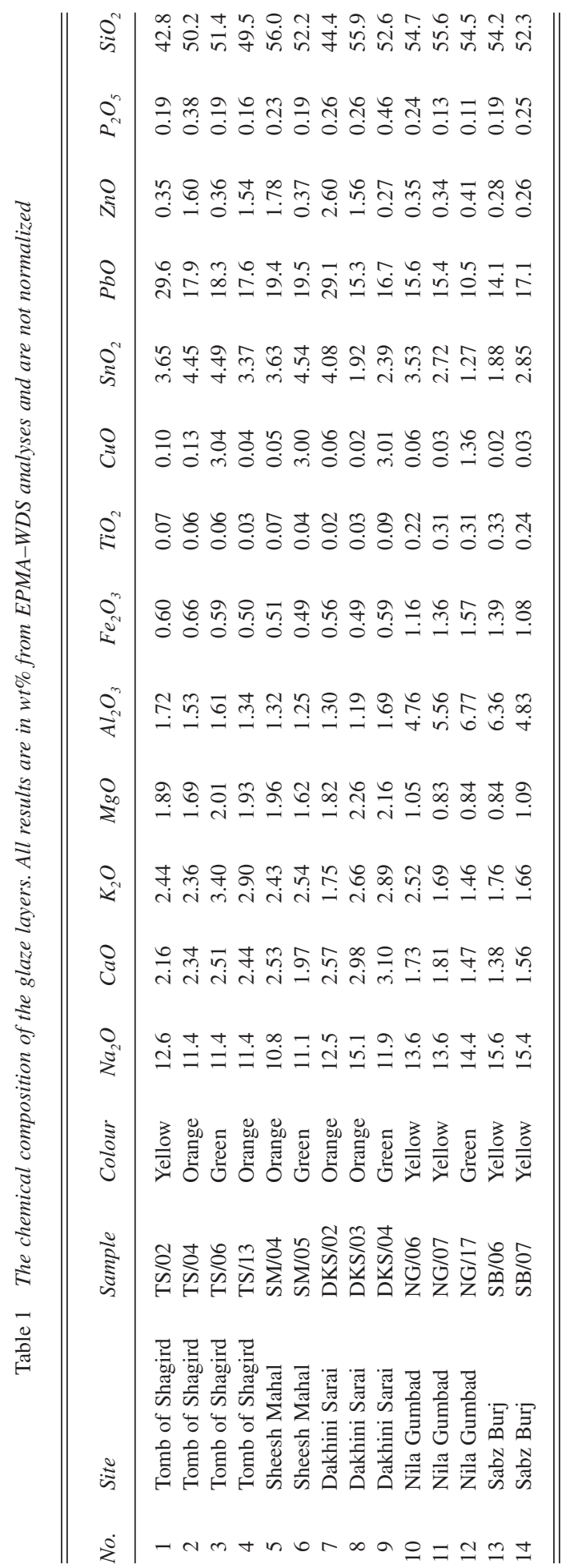




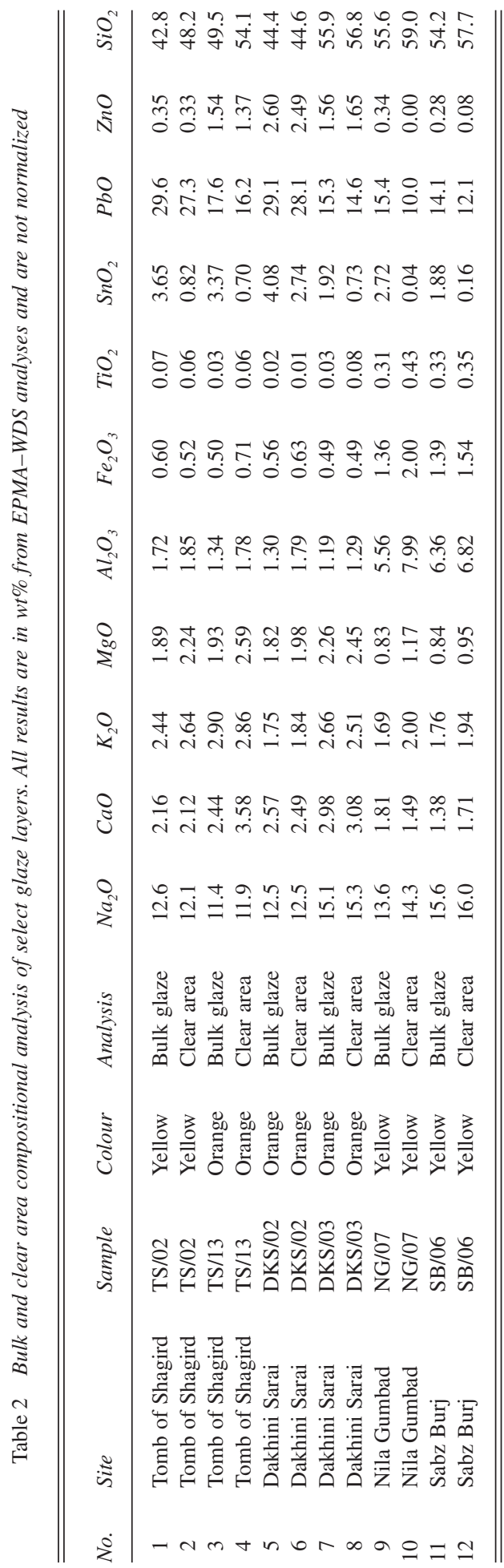




\section{Spot analysis}

Spot analyses across a random selection of bright particles in the yellow/green glazes from the sites identify them as being lead-tin yellow, mostly of the well-known type II with associated silica content. Amongst these glazes, all the Delhi yellow glazes and one Punjab green glaze were found to contain zinc-associated lead-tin orange particles as well (Table 3). In contrast, all the particles in the orange glazes are found to be solely of the zinc-rich compound, lead-tin orange. Only lead-tin orange particles are thus identifiable in the glaze layers of TS/04, TS/13, SM/04 and DKS/02; both types, with either zinc or silica, in NG/06, NG/07, SB/06, SB/07 and DKS/04; and with only associated silica content in TS/02, TS/06 and SM/05.

Atomic ratios of the constituents in both particle types are markedly consistent across all the sites, but significantly different between the two types. As expected from the formula for lead-tin yellow, the sum of the atom per cent of tin and silicon is close to the atom per cent of lead. This is consistent with the idea that in lead-tin yellow type II, $\mathrm{Si}^{4+}$ substitutes for $\mathrm{Sn}^{4+}$ in the basic formula $\mathrm{PbSnO}_{3}$. In contrast, the atom per cent levels for tin and lead are very similar to each other in the lead-tin orange particles, with the level of zinc being about one third of that of either lead or tin. Further research will have to address where the $\mathrm{Zn}^{2+}$ ions sit in the structure, taking up about $15 \%$ of all metal positions while keeping the valency balance intact.

\section{Textural characteristics}

The shape, size and distribution of pigment particles in the glazes vary dependent on the glaze colour. In the yellow glazes from Delhi, particles of lead-tin orange are quickly identifiable, being found in close proximity to lead-tin yellow particles, often together in a cluster, whereas their location in the Punjab glazes is difficult to ascertain and may only be surmised from the zinc oxide values returned in the bulk analysis. Particles in the orange glazes are relatively larger in size, in the range of 5-10 $\mu \mathrm{m}$ across with a substantial number at the higher end, as opposed to the yellow/green glazes where they are smaller, seldom exceeding $5 \mu \mathrm{m}$ in length or width. A comparatively uniform distribution of particles across the thickness of the glazes is noticeable not only for the orange-coloured glaze, but for all glazes from the Punjab sites in general, the yellow glazes from the Tomb of Shagird having a particularly dense concentration of the colourant (Fig. 3). On the other hand, the lead-tin yellow particles in glazes from Delhi, although dispersed through the glaze, are present in lesser density, at places occurring in small clusters of large and small particles (Fig. 4). In general, both angular and equant elongated particles, sometimes with conchoidal fractures, are found across all glazes. The larger ones are more often than not equant, especially in the orange glazes (Fig. 5).

It is unclear at present whether the pigment particles were added to the glaze frit as ready-made particles, or whether at least some of them crystallized from the melt. The conchoidal fracture and clustered appearance of many particles indicate that they were added as a separately made pigment, while the angular shape, regular grain size and even distribution of others could indicate their formation in situ from the melt. In many much earlier glasses, such lead-rich pigments are often bound to streaks of lead-rich glass within an alkali glass matrix, suggesting their being added as a pigment into a clear base glass (Shortland 2002; Heck et al. 2003). Here, distribution maps for lead oxide show an even distribution of lead oxide across the glaze; however, in the one sample studied so far it is noticeable that the zinc oxide content is higher around clusters of lead-tin orange, suggesting that the pigment was added into a clear glass or frit, and partly dissolved. Research is ongoing to systematically test the distribution of tin, lead and zinc in the 
Table 3 Results of spot analyses of lead-tin yellow particles in yellow, green and orange glazes through SEM-EDS and EPMA-WDS. Results from SEM-EDS have been normalized to 100\%; results from EPMA-WDS analyses are not normalized. The balance to 100 in at\% is oxygen. The ideal compound $\mathrm{PbSnO}_{3}$ would have 20 at\% $\mathrm{Pb}, 20$ at\% Sn and 60 at\% O; deviations from these figures are due to non-ideal crystal compositions and analytical error from the instrument

\begin{tabular}{|c|c|c|c|c|c|c|c|c|c|c|c|c|}
\hline \multirow[t]{2}{*}{ No. } & \multirow[t]{2}{*}{ Sample } & \multirow[t]{2}{*}{ Tile colour } & \multirow[t]{2}{*}{ Analysis } & \multirow[t]{2}{*}{ Particle } & \multicolumn{4}{|c|}{$W t \%$} & \multicolumn{4}{|c|}{$A t \%$} \\
\hline & & & & & $\mathrm{SiO}_{2}$ & $\mathrm{ZnO}$ & $\mathrm{SnO}_{2}$ & $\mathrm{PbO}$ & Si & $Z n$ & $S n$ & $P b$ \\
\hline 1 & $\mathrm{TS} / 02$ & Yellow & EDS & I & 5.0 & & 31.4 & 63.6 & 5.8 & & 14.4 & 19.7 \\
\hline 2 & $\mathrm{TS} / 02$ & Yellow & EDS & II & 4.8 & & 32.0 & 63.3 & 5.5 & & 14.7 & 19.7 \\
\hline 3 & $\mathrm{TS} / 02$ & Yellow & EDS & III & 5.6 & & 30.5 & 64.0 & 6.4 & & 13.9 & 19.6 \\
\hline 4 & $\mathrm{TS} / 02$ & Yellow & EDS & IV & 5.6 & & 30.3 & 64.1 & 6.4 & & 13.8 & 19.7 \\
\hline 5 & $\mathrm{TS} / 02$ & Yellow & EDS & $\mathrm{V}$ & 6.2 & & 30.4 & 63.4 & 6.9 & & 13.6 & 19.1 \\
\hline 6 & $\mathrm{TS} / 04$ & Orange & EDS & I & & 6.8 & 37.3 & 56.0 & & 5.9 & 17.6 & 17.8 \\
\hline 7 & $\mathrm{TS} / 04$ & Orange & EDS & II & & 6.7 & 37.7 & 55.7 & & 5.8 & 17.7 & 17.7 \\
\hline 8 & $\mathrm{TS} / 04$ & Orange & EDS & III & & 6.5 & 37.1 & 56.6 & & 5.7 & 17.6 & 18.2 \\
\hline 9 & $\mathrm{TS} / 04$ & Orange & EDS & IV & & 6.7 & 37.4 & 55.9 & & 5.8 & 17.6 & 17.8 \\
\hline 10 & $\mathrm{TS} / 04$ & Orange & EDS & $\mathrm{V}$ & & 9.1 & 38.1 & 52.8 & & 7.7 & 17.4 & 16.3 \\
\hline 11 & TS/06 & Green & EDS & I & 5.7 & & 32.1 & 62.3 & 6.4 & & 14.4 & 18.9 \\
\hline 12 & TS/06 & Green & EDS & II & 5.2 & & 32.6 & 62.2 & 5.9 & & 14.8 & 19.0 \\
\hline 13 & TS/06 & Green & EDS & III & 5.3 & & 31.2 & 63.6 & 6.0 & & 14.2 & 19.6 \\
\hline 14 & TS/06 & Green & EDS & IV & 5.7 & & 31.5 & 62.8 & 6.5 & & 14.1 & 19.6 \\
\hline 15 & $\mathrm{TS} / 13$ & Orange & EDS & I & & 6.5 & 36.3 & 57.2 & & 5.7 & 17.3 & 18.4 \\
\hline 16 & $\mathrm{TS} / 13$ & Orange & EDS & II & & 5.9 & 35.8 & 58.3 & & 5.3 & 17.2 & 18.9 \\
\hline 17 & $\mathrm{TS} / 13$ & Orange & EDS & III & & 6.3 & 36.1 & 57.6 & & 5.6 & 17.2 & 18.6 \\
\hline 18 & $\mathrm{TS} / 13$ & Orange & EDS & IV & & 6.2 & 35.8 & 58.0 & & 5.5 & 17.2 & 18.8 \\
\hline 19 & $\mathrm{TS} / 13$ & Orange & EDS & $\mathrm{V}$ & & 6.3 & 36.4 & 57.4 & & 5.5 & 17.3 & 18.5 \\
\hline 20 & $\mathrm{SM} / 04$ & Orange & EDS & I & & 6.7 & 38.0 & 55.3 & & 5.8 & 17.8 & 17.5 \\
\hline 21 & SM/04 & Orange & EDS & II & & 6.9 & 37.2 & 56.0 & & 6.0 & 17.5 & 17.8 \\
\hline 22 & SM/04 & Orange & EDS & III & & 6.2 & 37.2 & 56.6 & & 5.4 & 17.7 & 18.1 \\
\hline 23 & SM/04 & Orange & EDS & IV & & 6.9 & 36.9 & 56.3 & & 6.0 & 17.4 & 17.9 \\
\hline 24 & $\mathrm{SM} / 05$ & Green & EDS & I & 4.8 & & 32.3 & 62.8 & 5.6 & & 14.8 & 19.4 \\
\hline 25 & $\mathrm{SM} / 05$ & Green & EDS & II & 5.4 & & 32.5 & 62.0 & 6.1 & & 14.7 & 18.9 \\
\hline 26 & $\mathrm{SM} / 05$ & Green & EDS & III & 5.2 & & 32.6 & 62.3 & 5.9 & & 14.8 & 19.0 \\
\hline 27 & $\mathrm{SM} / 05$ & Green & EDS & IV & 7.0 & & 33.9 & 59.1 & 7.5 & & 14.5 & 17.0 \\
\hline 28 & NG/06 & Yellow & EDS & I & 5.4 & & 29.5 & 65.1 & 6.2 & & 13.6 & 20.2 \\
\hline 29 & NG/06 & Yellow & EDS & II & & 6.5 & 36.2 & 57.2 & & 5.8 & 17.2 & 18.4 \\
\hline 30 & NG/07 & Yellow & EDS & I & 5.2 & & 31.3 & 63.5 & 5.9 & & 14.3 & 19.6 \\
\hline 31 & NG/07 & Yellow & EDS & II & 4.8 & & 27.6 & 67.6 & 5.7 & & 13.2 & 21.8 \\
\hline 32 & NG/07 & Yellow & EDS & III & & 12.8 & 33.7 & 53.5 & & 10.8 & 15.3 & 16.4 \\
\hline 33 & NG/07 & Yellow & EDS & IV & 5.4 & & 31.0 & 63.6 & 6.2 & & 14.1 & 19.6 \\
\hline 34 & NG/07 & Yellow & EDS & V & & 6.5 & 37.1 & 56.4 & & 5.7 & 17.6 & 18.0 \\
\hline 35 & $\mathrm{SB} / 06$ & Yellow & EDS & I & 4.6 & & 30.4 & 65.0 & 5.4 & & 14.2 & 20.5 \\
\hline 35 & $\mathrm{SB} / 06$ & Yellow & EDS & II & & 6.5 & 37.1 & 56.4 & & 5.7 & 17.5 & 18.0 \\
\hline 36 & $\mathrm{SB} / 06$ & Yellow & EDS & III & 5.4 & & 27.4 & 67.2 & 6.3 & & 12.8 & 21.2 \\
\hline 37 & $\mathrm{SB} / 06$ & Yellow & EDS & IV & & 5.7 & 36.3 & 58.0 & & 5.1 & 17.4 & 18.8 \\
\hline 38 & $\mathrm{SB} / 07$ & Yellow & EDS & I & & 6.0 & 36.9 & 57.1 & & 5.3 & 17.6 & 18.4 \\
\hline 39 & $\mathrm{SB} / 07$ & Yellow & EDS & II & 5.4 & & 31.3 & 63.3 & 6.2 & & 14.2 & 19.4 \\
\hline 40 & $\mathrm{SB} / 07$ & Yellow & EDS & III & & 6.2 & 37.2 & 56.6 & & 5.4 & 17.7 & 18.1 \\
\hline 41 & $\mathrm{SB} / 07$ & Yellow & EDS & IV & & 6.9 & 36.9 & 56.3 & & 6.0 & 17.4 & 17.9 \\
\hline 42 & $\mathrm{SB} / 07$ & Yellow & WDS & I & & 5.4 & 34.2 & 57.7 & & 6.7 & 22.6 & 25.9 \\
\hline 43 & $\mathrm{SB} / 07$ & Yellow & WDS & II & 4.2 & & 29.7 & 62.9 & 7.0 & & 19.7 & 28.2 \\
\hline 44 & $\mathrm{SB} / 06$ & Yellow & WDS & I & & 5.4 & 34.6 & 58.3 & & 6.7 & 22.9 & 26.1 \\
\hline 45 & $\mathrm{SB} / 06$ & Yellow & WDS & II & 6.5 & & 29.7 & 61.6 & 10.8 & & 19.7 & 27.6 \\
\hline 46 & $\mathrm{SB} / 06$ & Yellow & WDS & III & 4.2 & & 29.1 & 63.5 & 7.0 & & 19.3 & 28.5 \\
\hline 47 & DKS/02 & Orange & WDS & I & & 6.5 & 35.5 & 56.3 & & 8.0 & 23.5 & 25.2 \\
\hline 48 & DKS/02 & Orange & WDS & II & & 6.0 & 34.0 & 56.7 & & 7.4 & 22.5 & 25.4 \\
\hline 49 & DKS/04 & Green & WDS & I & & 5.9 & 34.5 & 53.3 & & 7.3 & 22.8 & 23.9 \\
\hline 50 & DKS/04 & Green & WDS & II & 4.8 & & 29.2 & 65.8 & 8.0 & & 19.3 & 29.5 \\
\hline
\end{tabular}




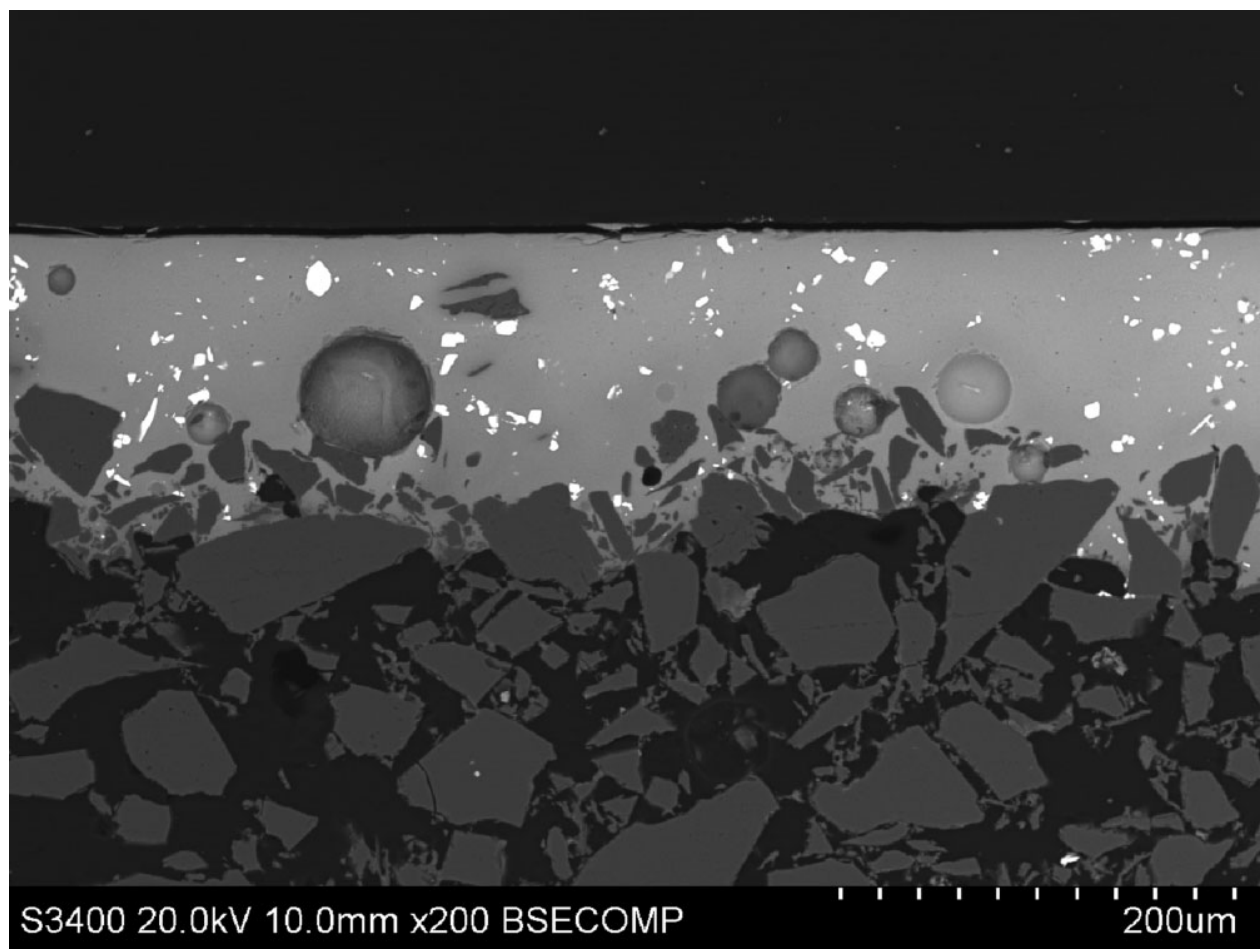

Figure 3 A backscattered electron SEM micrograph illustrating the even distribution of pigment particles across an orange glaze from Sheesh Mahal (SM/04).

different glaze types and locations, to gain a representative picture of the manner in which the pigment was either added or formed in the glaze.

The partial dissolution of lead-tin orange is also noticeable from the shape of the individual particles and the zinc content in the surrounding glaze. Blurred borders of particles from the sites in Punjab are associated with comparable values of zinc oxide in bulk and small area analysis in clear glaze, whereas in the Delhi glazes, the low concentrations or near-total lack of zinc oxide in clear portions of the glaze is seemingly linked to the sharper boundaries of the particles with zinc content. Notably, however, the blurring of particle boundaries in the orange glazes is also associated with size, as it is the smaller particles, $<5 \mu \mathrm{m}$, that have diffused edges, with larger ones retaining their distinct shapes.

\section{Raman spectroscopy}

Raman spectra were collected from randomly selected orange particles in the orange glazes of $\mathrm{TS} / 04$ and TS/13, and from yellow particles in the yellow glaze of TS/02. The spectrum for the yellow particles obtained at $780 \mathrm{~nm}$ excitation is characterized by an intense band at $141 \mathrm{~cm}^{-1}$ and a weaker broad band at $331 \mathrm{~cm}^{-1}$. This is in close agreement with that recorded by Clark et al. (1995) for lead-tin yellow type II. The spectrum associated with the orange particles is quite different from the reference, for this excitation wavelength, with very strong bands in this case 


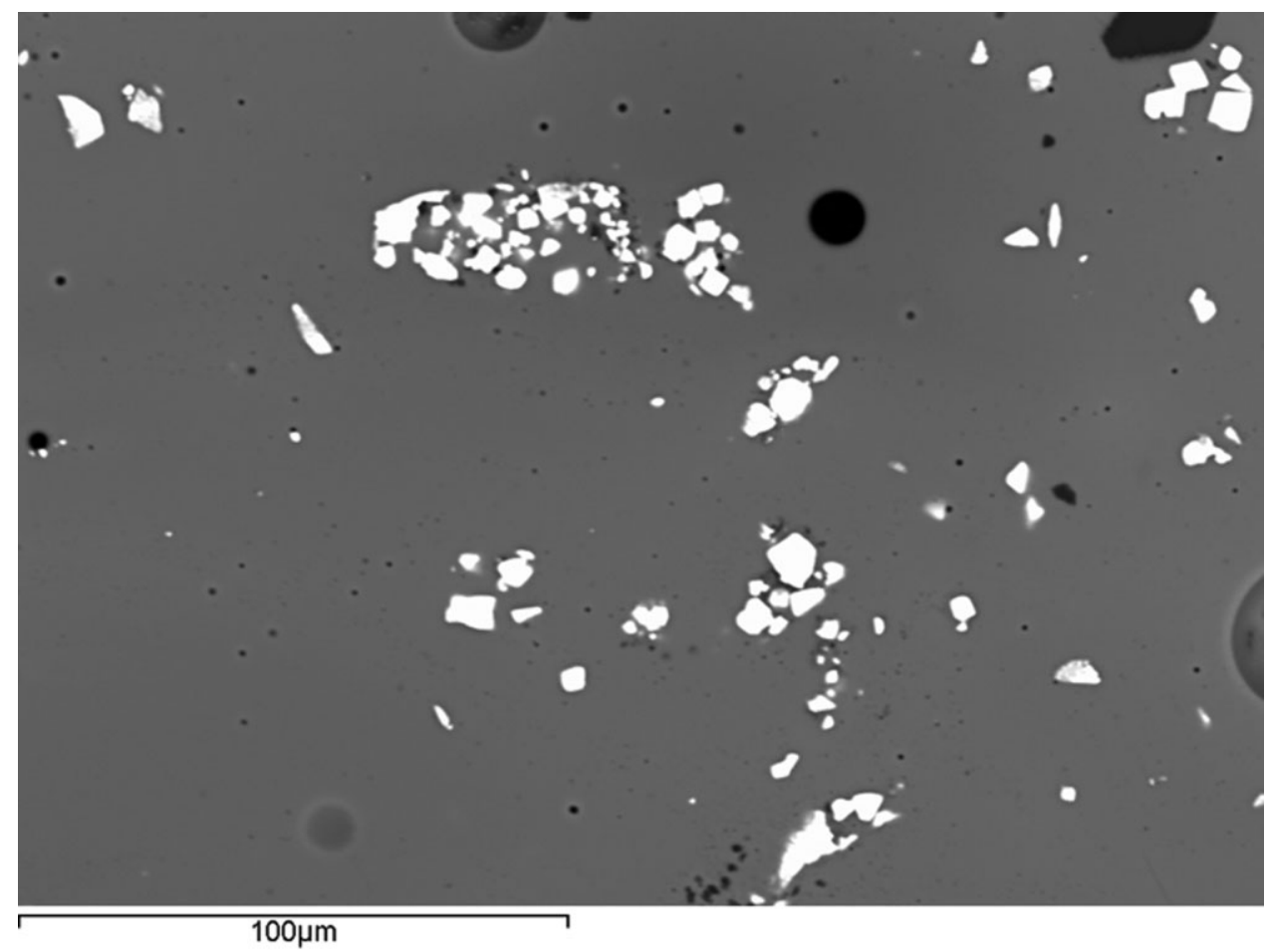

Figure 4 A backscattered electron SEM micrograph of a yellow glaze (SB/06) from Sabz Burj, Delhi. Pigment particles, while distributed across the glaze in the Delhi samples, are quite often in clusters of large and small particles, as can be seen in this image.

found at $118 \mathrm{~cm}^{-1}$ and $144 \mathrm{~cm}^{-1}$ and weaker broad bands at $286 \mathrm{~cm}^{-1}, 335 \mathrm{~cm}^{-1}, 440 \mathrm{~cm}^{-1}$ and $539 \mathrm{~cm}^{-1}$ (Figs 6 (a) and 6 (b)). An apparent resemblance between the orange particle spectrum and spectra recorded by Gulzar et al. (2012) from orange particles in yellow Mughal glazes at Lahore is, however, noticeable. At $532 \mathrm{~nm}$ excitation, a marginal shift is noticeable in the orange particle spectrum, a strong band now being found at $139 \mathrm{~cm}^{-1}$, and weaker bands at $282 \mathrm{~cm}^{-1}$, $337 \mathrm{~cm}^{-1}, 430 \mathrm{~cm}^{-1}$ and $533 \mathrm{~cm}^{-1}$.

\section{DISCUSSION}

Tiles with orange, yellow, and green glazes in Mughal Islamic India are by no means limited to the sampled monuments or to the period of the sampled specimens. Yellow and green glazes are found in several pre-Mughal monuments from the Sultanate period (1206-1526) in other regions in the subcontinent (Furnival 1904; Nath 1989). Orange-coloured glazes are also found elsewhere. They are, however, a comparatively later development, only clearly in use by the late 16th century, as on the tomb of Sultan Ibrahim Qutb Shah at Golconda in the Deccan, before their widespread employment in the north under the Mughals during the first half of the 17th century (Parihar 1985; Nath 1989).

While previous studies have demonstrated the occurrence of lead-tin orange along with the dominant lead-tin yellow pigment in Mughal 17th-century yellow and green glazes (Gill and 


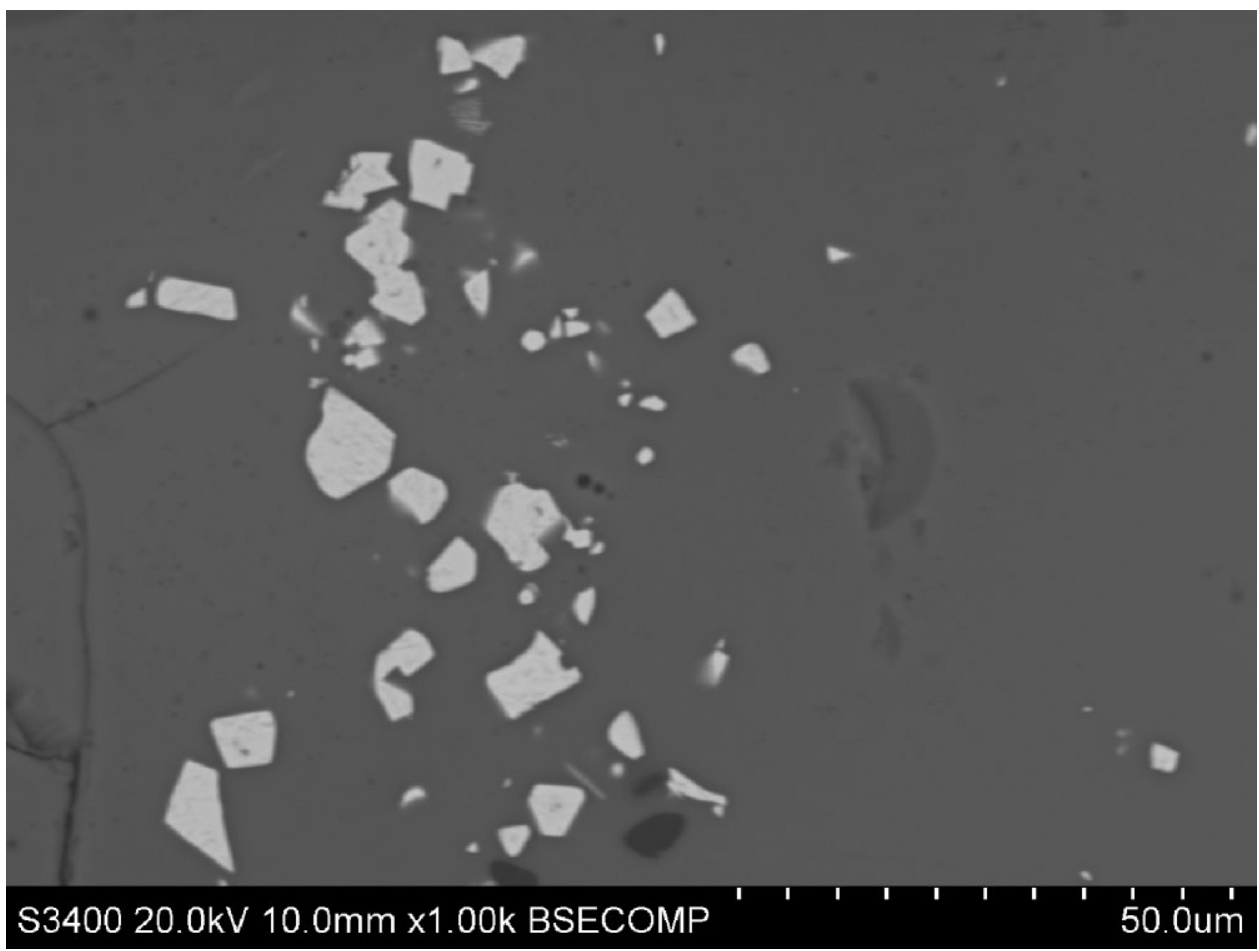

Figure 5 A high-magnification backscattered electron SEM micrograph of a group of angular and largely equant pigment particles in the orange glaze TS/04. Clusters of large particles such as this are unusual for tile-mosaic glazes, the particles being generally well distributed.

Rehren 2011; Gulzar et al. 2012), its clearly detected presence in orange-coloured glazed tiles now confirms its use in contemporary orange glazes as well. The exclusive presence of lead-tin orange in the orange-coloured glazes, as opposed to yellow/green glazes with predominantly lead-tin yellow, is suggestive of controlled manufacture with the intent of producing the resultant shade, supported by the artistic scheme of extant tile-work on the monuments where the tiles can be seen to be deliberately employed in the colours that they are. The fact that we find orange tiles only in the Punjab monuments bearing the true tile-mosaic may be attributable to an aesthetic appeal linked with this form of tile-work or regional preferences in terms of desired colour schemes. Alternatively, the production of orange glazes may have been known only to the tile-mosaic artisans, who kept the recipe a closely guarded secret, but this seems less likely given the presence of lead-tin orange particles in yellow/green glazes of other tile forms as well, along with regular lead-tin yellow type II.

The consistency in atomic ratios of the constituents in both lead-tin yellow and lead-tin orange observed across the monuments irrespective of region or tile-work forms also indicates a controlled and intentional manufacture of both pigments. The orange pigment could have been produced directly by heating a mixture of the necessary raw materials, or in two stages by heating pre-synthesized lead-tin yellow with a zinc compound. The presence of some lead-tin orange particles in yellow or green glazes could indicate that the artisans added a quantity of orange pigment to the yellow in order to obtain a more saturated hue. Alternatively, it could result from simple contamination in a workshop producing or handling both pigments side by side. 
(a)

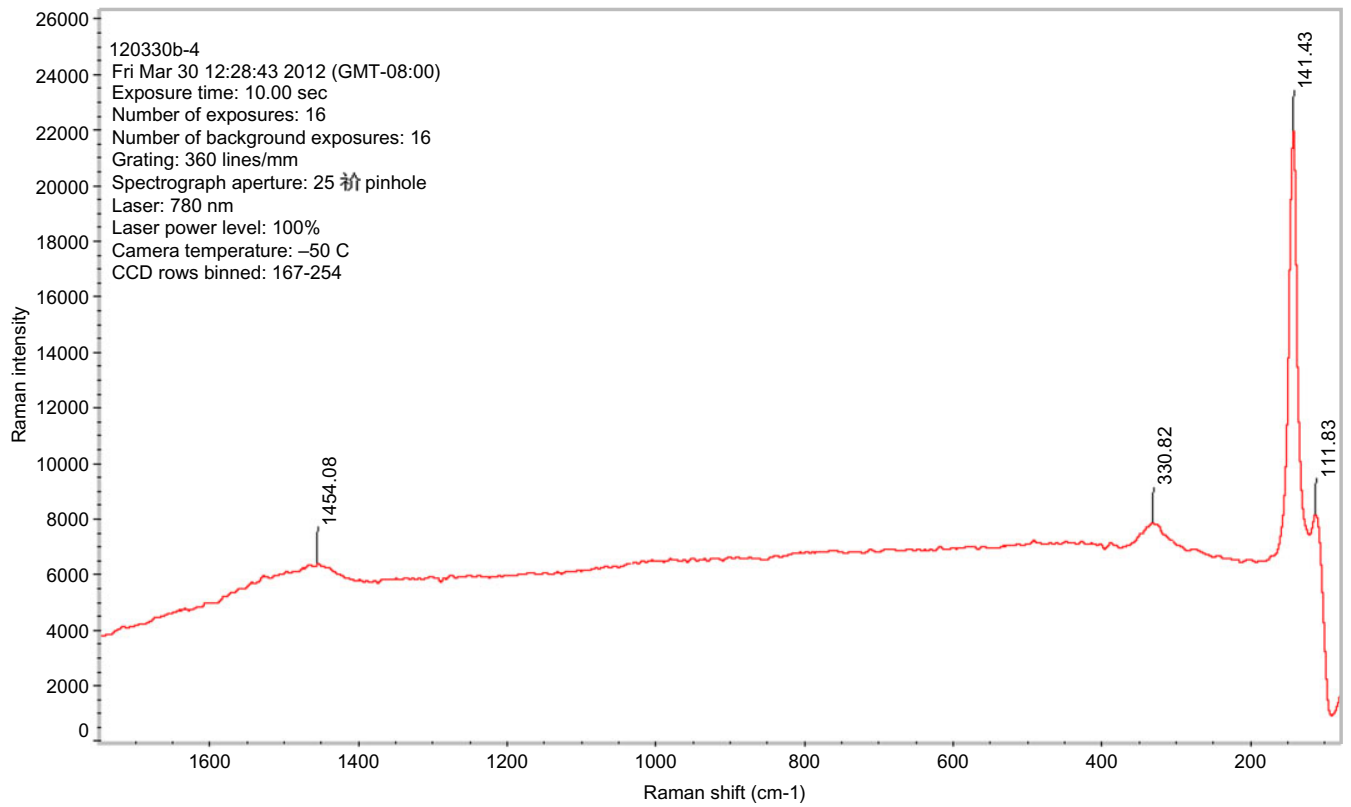

(b)

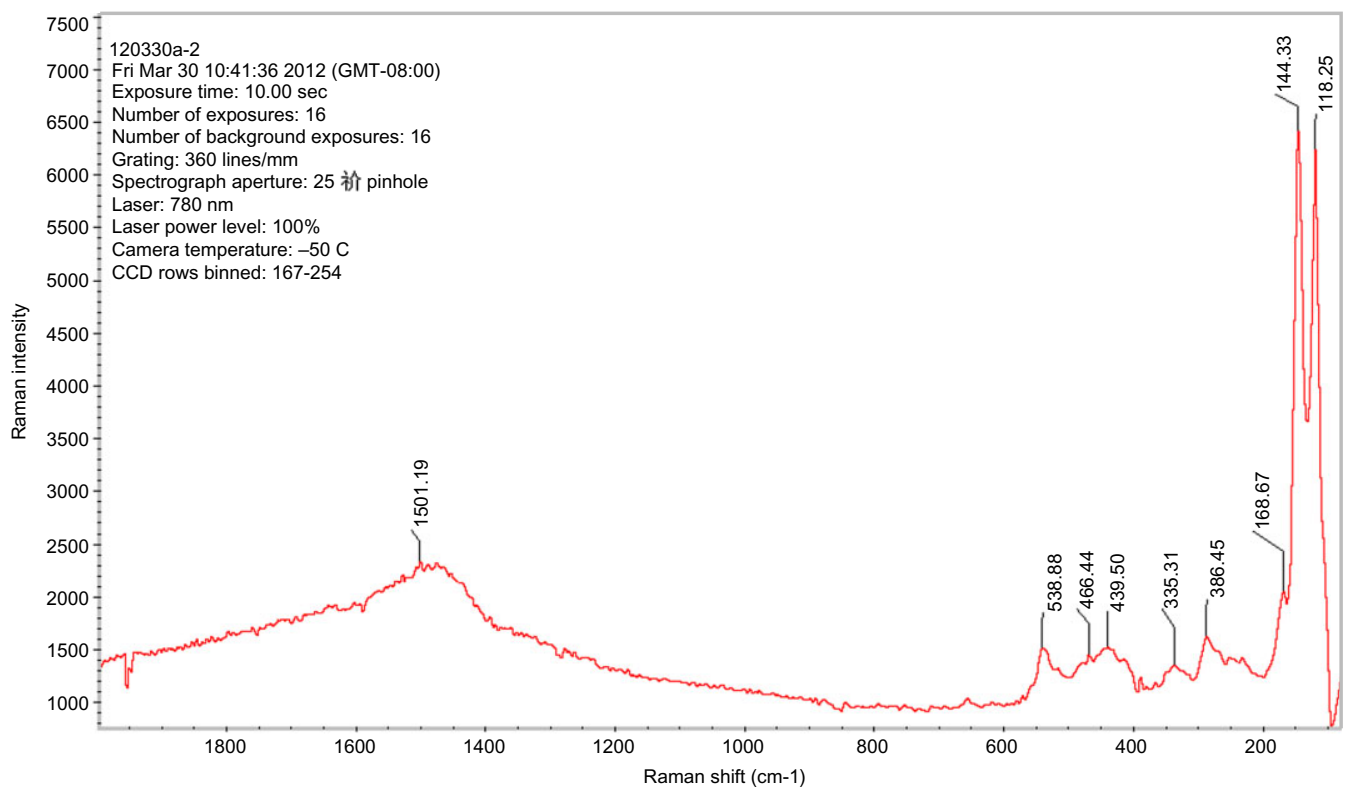

Figure 6 (a) A Raman spectrum obtained from yellow particles in the yellow glaze TS/02. (b) A Raman spectrum obtained from orange particles in the orange glazes TS/04 and TS/13. 
Experimental work would have to clarify whether the addition of some zinc oxide into the batch material for the manufacture of lead-tin yellow type II would result in the formation of a small amount of discrete lead-tin orange particles, or in the uptake of minor amounts of zinc in the regular lead-tin yellow structure. Work by Rosi et al. (2009) on the possible existence of an orange-yellow lead-antimonate by the addition of zinc oxide, based on the revised interpretation of a 16th-century recipe attributed to Piccolpasso, may also be noted in this context, the pigment lead-antimonate yellow having a history of use as an alternative to lead-tin yellow over the ages.

The presence of zinc in place of silica and variations in the Raman bands obtained for lead-tin orange from the known spectrum of the lead-tin yellow type II form is suggestive of the existence of a modified crystal structure of the lead-tin orange pigment. The exact extent to which zinc replaces tin and/or lead and refinement of the structural model would require further investigations. For the moment, a distinction in the composition and atomic ratios of the two particle types, 1:3:3 of zinc:tin:lead and 1:2.3:3.3 of silica:tin:lead, may be taken as further evidence of structural dissimilarity and considered in the firm derivation of a possible nominal formula for the zinc-associated particle type.

\section{CONCLUSION}

We have shown that a hitherto little-known artificial orange pigment, dubbed lead-tin orange in parallel to the better-known lead-tin yellow, has been consistently produced and intentionally used in Mughal India, particularly in the early to middle 17th century. Pure orange-glazed tiles with the pigment are known only from the Punjab tile-mosaic form, but lead-tin orange particles were found also within the matrix of yellow and green glazes at Delhi coloured by lead-tin yellow type II. We assume that the presence of lead-tin orange particles in the Delhi tiles is due to their addition to the yellow pigment in order to improve the yellow hue. The orange colour is linked to the presence of around 6-7 wt $\%$ zinc oxide in the pigment, and the absence of silica. The replacement mechanism that enables the zinc ions to enter the lead-tin oxide structure is not yet understood, and does not seem to follow a simple substitution of $\mathrm{Pb}^{2+}$ by $\mathrm{Zn}^{2+}$.

\section{ACKNOWLEDGEMENTS}

We are grateful to the Indian authorities in charge of the monuments for permissions accorded, and for assisting us in this research. Kevin Reeves from the UCL Institute of Archaeology is warmly thanked for his assistance with EPMA and SEM-EDS analyses. Thanks are also due to Dr Xiaolin Cheng from the Conservation Centre, National Museum of China, for the Raman analyses. Comments from two anonymous reviewers are gratefully acknowledged; any remaining errors are ours. This work is part of the first author's doctoral research at UCL Qatar, generously funded by QF and QMA under a contract with UCL to establish UCL Qatar.

\section{REFERENCES}

Clark, R., Cridland, L., Kariuki, B., Harris, K., and Withnall, R., 1995, Synthesis, structural characterisation and Raman spectroscopy of the inorganic pigments lead tin yellow types I and II and lead antimony yellow: their identification on medieval paintings and manuscripts, Journal of the Chemical Society, Dalton Transactions, 16, 2577-82.

Dussubieux, L., Gratuze, B., and Blet-Lemarquand, M., 2010, Mineral soda alumina glass: occurrence and meaning, Journal of Archaeological Science, 37, 1646-55.

Furnival, W. J., 1904, Leadless decorative tiles, faience and mosaic, Stone, Staffordshire, UK.

Gill, M. S., and Rehren, Th., 2011, Material characterization of ceramic tile mosaic from two 17th century monuments in northern India, Archaeometry, 53, 22-36. 
Gulzar, S., Worle, M., Burg, J., Chaudhry, M. N., and Joseph, E., 2012, Characterization of 17th century Mughal tile glazes from Shahdara complex Lahore-Pakistan, Journal of Cultural Heritage, doi:10.1016/j.culher.2012.03.007.

Heck, M., Rehren, Th., and Hoffmann, P., 2003, The production of lead-tin yellow at Merovingian Schleitheim (Switzerland), Archaeometry, 45, 33-44.

Kühn, H., 1968, Lead-tin yellow, Studies in Conservation, 13, 7-33.

Mason, R. B., and Tite, M. S., 1994, The beginnings of Islamic stonepaste technology, Archaeometry, 36, 77-91.

Nath, R., 1989, Colour decoration in Mughal architecture (India and Pakistan), The Historical Research Documentation Programme, Jaipur.

Parihar, S., 1985, Mughal monuments in the Punjab and Haryana, Inter-India Publications, New Delhi.

Rooksby, H. P., 1964, A yellow cubic lead tin oxide opacifier in ancient glasses, Physics and Chemistry of Glasses, 5 , 20-5.

Rosi, F., Manuali, V., Miliani, C., Brunetti, B. G., Sgamellotti, A., Grygar, T., and Hradil, D., 2009, Raman scattering features of lead pyroantimonate compounds, part 1: XRD and Raman characterization of $\mathrm{Pb}_{2} \mathrm{Sb}_{2} \mathrm{O}_{7}$ doped with tin and zinc, Journal of Raman Spectroscopy, 40, 107-11.

Shortland, A. J., 2002, The use and origin of antimonate colorants in early Egyptian glass, Archaeometry, 44, 517-31.

Tite, M., Pradell, T., and Shortland, A., 2008, Discovery, production and use of tin-based opacifiers in glasses, enamels and glazes from the late Iron Age onwards: a reassessment, Archaeometry, 50, 67-84. 